\title{
Cellular interaction of folic acid conjugated superparamagnetic iron oxide nanoparticles and its use as contrast agent for targeted magnetic imaging of tumor cells
}

\author{
This article was published in the following Dove Press journal: \\ International Journal of Nanomedicine \\ 5 July 2012 \\ Number of times this article has been viewed
}

\section{Manoj Kumar' \\ Gurpal Singh' \\ Vikas Arora ${ }^{2}$ \\ Sujeet Mewar ${ }^{3}$ \\ Uma Sharma ${ }^{3}$ \\ NR Jagannathan ${ }^{3}$ \\ Sameer Sapra ${ }^{2}$ \\ Amit K Dinda 4 \\ Surender Kharbanda ${ }^{5}$ \\ Harpal Singh' \\ 'Center for Biomedical Engineering, Indian Institute of Technology, Hauz Khas, New Delhi-I 10016 , India; ${ }^{2}$ Department of Chemistry, Indian Institute of Technology, Delhi Hauz Khas, New Delhi-II00I6, India; \\ ${ }^{3}$ Department Of NMR, All India Institute of Medical Sciences, Ansari Nagar New Delhi-I I0029, India; ${ }^{4}$ Department Of Pathology, All India Institute of Medical Sciences, Ansari Nagar New Delhi-I I0029, India; ${ }^{5}$ Department of Medical Oncology, Dana-Farber Cancer Institute, Harvard Medical School, Boston, MA 02115, USA}

Correspondence: Harpal Singh Center for Biomedical Engineering, Indian Institute of Technology, Hauz Khas, New Delhi-I I0016, India Tel +9| I| 659 | | 49

Email harpal2000@yahoo.com

Amit K Dinda

Department of Pathology, All India Institute of Medical Sciences, Ansari Nagar, New Delhi-I I0029, India Tel +9। I I 26588233

Fax +9। II 658866326588789

Email amit_dinda@yhaoo.com
Abstract: The purpose of the study was to develop tumor specific, water dispersible superparamagnetic iron oxide nanoparticles (SPIONs) and evaluate their efficacy as a contrast agent in magnetic resonance imaging (MRI). We have developed SPIONs capped with citric acid/2-bromo-2-methylpropionic acid which are compact, water dispersible, biocompatible having narrow range of size dispersity $(8-10 \mathrm{~nm})$, and relatively high $\mathrm{T}_{2}$ relaxivity $\left(\mathrm{R}_{2}=222 \mathrm{~L} \cdot \mathrm{mmol}^{-1} \cdot \mathrm{sec}^{-1}\right)$. The targeting efficacy of unconjugated and folic acid-conjugated SPIONs (FA-SPIONS) was evaluated in a folic acid receptor overexpressing and negative tumor cell lines. Folic acid receptor-positive cells incubated with FA-SPIONs showed much higher intracellular iron content without any cytotoxicity. Ultrastructurally, SPIONs were seen as clustered inside the various stages of endocytic pathways without damaging cellular organelles and possible mechanism for their entry is via receptor mediated endocytosis. In vitro MRI studies on tumor cells showed better $\mathrm{T}_{2}$-weighted images in FA-SPIONs. These findings indicate that FA-SPIONs possess high colloidal stability with excellent sensitivity of imaging and can be a useful MRI contrast agent for the detection of cancer.

Keywords: superparamagnetic iron oxide nanoparticles (SPION), cellular internalization, magnetic resonance imaging (MRI), cancer-cell targeting ligand

\section{Introduction}

Super paramagnetic iron oxide nanoparticles (SPIONs) have garnered increased attention for their role in biomedical applications such as targeted delivery, localized therapy, stem cell labeling, tracking, and as contrast agents for magnetic resonance imaging (MRI). ${ }^{1-3}$ Currently, a number of SPIONs are either in early stage clinical trials or in preclinical studies. ${ }^{1,4}$ Some examples are: Lumiren for bowel imaging, ${ }^{5}$ Feridex $4^{\circledR}$ for liver and spleen imaging, ${ }^{6}$ Combidex for lymph node metastases imaging, ${ }^{7}$ and most recently, Ferumoxytol for iron replacement therapy. ${ }^{8}$ The physicochemical profiles of these SPIONs provide passive targeting, but not the higher level targeting offered by bioligands. Attachment of bioactive molecules to the SPION surface can potentially increase the targeting specificity of nanoparticles, ${ }^{4,9,10}$ producing contrast agents that specifically illuminate targeted tissue and drug carriers that do not interact with healthy tissue. ${ }^{6,10}$

The co-precipitation method is widely used for the synthesis of iron oxide nanoparticles, ${ }^{11}$ but nanoparticles obtained by this method have a broad range of size distribution and are also not highly stable. ${ }^{12}$ Currently, significant work on the 
development and characterization of SPIONs is underway. The creation of next generation SPIONs $\left(\mathrm{Fe}_{3} \mathrm{O}_{4}\right.$ and $\left.\gamma-\mathrm{Fe}_{2} \mathrm{O}_{3}\right)$ can be obtained by thermal decomposition methods. These SPIONs can be used as molecular imaging probes due to their high crystallinity and monodispersity. However they are only soluble in organic solvents due to the hydrophobic alkyl ligands on their surface. ${ }^{9,13-15}$ Water solubility and surface functionality are the two critical parameters necessary for interaction with biological systems. This includes surface coating or ligand exchange to make the SPIONs water dispersible. These surface coatings directly affect the biological activities of nanoparticles; in particular, cellular uptake, ${ }^{15}$ bio-distribution, ${ }^{16}$ blood circulation, ${ }^{17}$ and metabolism. ${ }^{18}$ Depending on the application, the efficacy of nanoparticles can be directly influenced by the surface coatings. All of these surface coatings, besides giving the SPIONs water solubility, also provide functional groups for the attachment of various ligands for targeted delivery or concentrating the resulting complexes to the desired locale. Targeting the SPION contrast agents to specifically accumulate in regions of interest greatly enhances their clinical utility. ${ }^{11,19,20}$ Other studies have demonstrated various approaches for active targeting of SPIONs including peptides, hormones, aptamers, antibodies, proteins, therapeutics, and nutrients. Antibodies are inherently immunogenic and are also bulky; both properties are believed to inhibit internalization of attached structures. ${ }^{21}$ The nutrient pathways are attractive since they are directly linked to proliferation and thus in principle will cause increased uptake of the imaging agent and therefore give greater signals for most tumor types. The folic acid receptor (FAR) is overexpressed in a wide variety of human tumors, as folic acid (FA) is a key precursor in DNA base synthesis and is thus required for tumor cell proliferation..$^{22-24}$

In the present study, we demonstrate that combining more than one ligand, as effective phase transfer agents for SPIONs to transfer them from the organic phase to the water phase, is crucial for their colloidal stability and clinical utility. These coatings act as stabilizers for the magnetite nanoparticles and also provide a functionality to attach biological moiety to target the particles to cells. Additionally, we have also studied the stability of water soluble FA-conjugated SPIONs. We have successfully demonstrated selective binding, effective uptake, and the kinetics of FA-conjugated SPIONs into various tumor cell lines. Furthermore, we have also demonstrated the magnetic resonance (MR) properties of FA-conjugated SPIONs. Our studies were directed towards increasing the concentration of SPIONs into tumor cells by conjugating SPIONs with a targeted ligand, folic acid (FA).
Internalization kinetics studies were performed in detail to optimize the maximum uptake of SPIONs into the tumor cells. The main aim of the present study was to design SPIONs, which can be used as a potential candidate for specific and sensitive cancer diagnosis.

\section{Materials and methods Materials}

Iron (3) chloride hexahydrate $\left(\mathrm{FeCl}_{3} \cdot 6 \mathrm{H}_{2} \mathrm{O}\right)$, 1-octadecene (ODE), oleic acid (99.5\%), folic acid, N-hydroxy succinamide (NHS), 1-ethyl-3-(-3-diethylaminopropyl)-carbodiimide (EDC), Dulbecco's Modified Eagle Medium (DMEM), fetal bovine serum (FBS), penicillin, and streptomycin were purchased from Sigma Aldrich (St Louis, MO). Sodium hydroxide, methanol (HPLC grade), toluene, potassium ferrocynide, DPX mount, and hydrochloric acid were purchased from Qualigens Fine Chemical (Mumbai, India).

\section{Methods}

\section{Synthesis of SPIONs}

The nanoparticles were synthesized according to protocol by Jana et $\mathrm{al}^{25}$ ligand exchange of oleic coated SPION with tetramethyl ammonium hydroxide (TMAOH) was done according to protocol by Salgueirino-Maceira et $\mathrm{al}^{26}$ and dimercaptosuccinic acid (DMSA) was done according to Chen et al. ${ }^{27}$

\section{Preparation of citric acid coated SPION}

Ligand exchange of oleic coated SPION with citric acid was done according to the procedures given by Lattuda and Hatton ${ }^{28}$ with slight modification. Oleic acid coated nanoparticles $(120 \mathrm{mg})$ prepared as described above were dispersed in a 1:1 mixture of 1,2-dichlorobenzene and N,N-dimethyl formamide ( $30 \mathrm{~mL}$ of total volume), to which $0.1 \mathrm{~g}$ of citric acid was added. The mixture was then stirred at $90^{\circ} \mathrm{C}$ for $\sim 12$ hours. The particles were subsequently precipitated by the addition of ethanol $(40 \mathrm{~mL})$ and separated using a magnet. The particles were redispersed in acetone and again separated by means of a magnet 3 to 4 times to remove all traces of free citric acid. The particles were then dried in a vacuum oven for 20 minutes at $80^{\circ} \mathrm{C}$.

\section{Preparation of citric acid/2-bromo-2-methylpropionic acid coated SPION (CA/BMPA-SPIONs)}

The procedure used here is identical to that described in citric acid coating of magnetic nanoparticles, ${ }^{28}$ with slight modification, wherein a mixture of $0.050 \mathrm{~g}$ of citric acid and $0.4 \mathrm{~g}$ of 2-bromo-2-methylpropionic acid was used for the 
ligand exchange reaction. Bio conjugation of CA/BMPA coated SPION with folic acid was done using the same procedures as You et al. ${ }^{29}$

\section{Prussian blue staining}

To demonstrate $\mathrm{Fe}$ in the target cells (MCF-7, HepG2, A549), $5 \times 10^{4}$ cells were seeded on coverslips in twelve well culture plates and grown for 24 hours. Then the cells were incubated with FA-SPION and non-conjugated SPIONs with different concentrations of SPION (25-200 $\mu \mathrm{g} / \mathrm{mL})$. After incubation of 6 hours, the coverslips were removed followed by washing with phosphate buffer saline (PBS) solution and finally fixed with $4 \%$ paraformaldehyde for 20 minutes at room temperature. After removing the fixing agent, the cells were washed and stained with Prussian blue iron stain. The SPIONs were labeled and the control cells were incubated with a $1: 1$ mixture of $4 \%$ potassium ferrocyanide and $4 \%$ hydrochloric acid for 20 minutes, and washed with distilled water several times. To stain the nuclei the cells were treated with nuclear fast red solution (Polysciences, Inc, Warrington, PA) for 5 minutes and then rinsed in running tap water for 1 minute. After drying the cells, a cover slip was mounted by using a mounting medium (Dako, Carpenteria, CA) and then the cells were observed using light microscopy (Olympus, Fluoview FV1000 Microscope, Japan).

\section{Transmission electron microscopy (TEM) study}

MCF-7 cells were grown in twelve well cell culture plates. After 48 hours FA-SPION $(100 \mu \mathrm{g} / \mathrm{mL})$ were added and incubated for different time intervals $(1,3$, and 6 hours) and the rest of the procedure was performed according to Zhou et al. ${ }^{30}$ Finally, samples were viewed under an electron microscope (Morgagni 268; Philips, Amsterdam, Netherlands).

\section{XTT assay}

A cytotoxicity test of the SPIONs was performed according to the manufacturer's protocol (Cayman Chemical Company, Ann Arbor, MI) as follows. A total of $5 \times 10^{4}$ cells were seeded on each well of a 96 -well plate and cultured for 24 hours. The cells were treated with different concentrations of SPION's $(62.5,125,250,500$, and $1000 \mu \mathrm{g} \mathrm{Fe} / \mathrm{mL})$ in a serum-free medium for 24 hours and 48 hours. After incubation, the medium containing SPION's was exchanged with a fresh medium, and $10 \mu \mathrm{L}$ of the reconstitute XTT mixture kit reagent were added to each well. After culturing for 4 hours, the absorbance of the sample was measured by using a microtiter plate reader (Bio-Rad, Hercules, CA) at $450 \mathrm{~nm}$. The viability of the cells was determined as the percentage of viable cells of the untreated control and analyzed in triplicate.

\section{Cellular uptake study}

To study the intracellular uptake of surface-modified nanoparticles, $1 \times 10^{5}$ cells were initially plated and grown to $60 \%$ confluence in twelve well culture plates. Cells were then washed twice with PBS and cultured in $10 \mathrm{~mL}$ of DMEM containing $10 \% \mathrm{FBS}$ and 1\% penicillin/streptomycin for 24 hours. The growth medium was then aspirated and the cells were washed twice with PBS. The effect of surface coating on the uptake of nanoparticles by MCF-7 and HepG2 cells was evaluated by culturing these cells with FA-SPION and unconjugated SPION, each dispersed in DMEM at a concentration range of $10-400 \mu \mathrm{g} \mathrm{Fe} / \mathrm{mL}$ for 6 hours. While in time-dependent study, cells were incubated with a fixed concentration of $100 \mu \mathrm{g} \mathrm{Fe} / \mathrm{mL}$ for different time intervals ranging from 0.5 to 12 hours. A plate of control cells was prepared in a similar manner without the addition of nanoparticles. At the end of incubation, cells were washed three times with PBS, detached with trypsin-EDTA, and resuspended in $1 \mathrm{~mL}$ of PBS containing 5\% FBS. Cell concentrations were determined by hemocytometer using trypan blue dye. The specific uptake of FA-SPION conjugates by MCF-7 and HepG2 cells was further examined in a competitive uptake inhibition assay, where FA-SPION was incubated with $10 \mathrm{mM}$ of free folic acid. To evaluate the specificity of cellular targeting of the nanoparticle conjugates, the uptake of FA-SPION conjugates by MCF-7 and HepG 2 cells was compared with the uptake by A549 cells that do not overexpress the folate receptor. A549 cells were cultured with different concentrations (10 to $400 \mu \mathrm{g} \mathrm{Fe} / \mathrm{mL}$ ) and for different time periods (0.5-12 hours) with FA-SPION and unconjugated SPION in a similar manner as with the MCF-7 and HepG 2 cells. The cells were then detached and counted as mentioned above. Intracellular uptake of the nanoparticles was quantified by atomic absorption spectroscopy (AAS), where a known number of cells from each sample were analyzed for iron content. AAS samples were prepared by centrifuging down the cells and dissolving the cell pellet in 37\% hydrochloric acid at $70^{\circ} \mathrm{C}$ for 3 hours. The samples were then diluted to a volume of $3 \mathrm{~mL}$ for analysis. Intracellular uptake experiments were performed in triplicate with percent error determined by calculating the standard deviation of these measurements.

\section{Magnetic resonance imaging}

\section{Preparation of phantom agar gels for imaging}

Suspensions of FA-SPION in the concentration range of $0-20 \mu \mathrm{g} / \mathrm{mL}$ of Fe were prepared in PBS. A $2.0 \% \mathrm{w} / \mathrm{v}$ agar 
solution was prepared by heating $200 \mathrm{mg}$ of agar in $10 \mathrm{~mL}$ of PBS at $80^{\circ} \mathrm{C}$ for 20 minutes. For preparing phantom gels, $160 \mu \mathrm{L}$ of the above agar solution was mixed thoroughly with vigorous shaking with $840 \mu \mathrm{L}$ of SPION suspension at each concentration at $60^{\circ} \mathrm{C}$ to prevent gelation while mixing and poured in $1.5 \mathrm{~mL}$ microcentrifuge tubes, followed by the cooling of the these tubes at room temperature.

A total of $5 \times 10^{4}$ cells were seeded on each well of a twelve-well plate and grown for 24 hours. The cells were then incubated with a medium containing different concentrations (40-160 $\mu \mathrm{g} / \mathrm{mL})$ of FA-SPION and unconjugated SPIONs. After 6 hours, the medium was removed and then the cells were washed with a PBS solution to remove free SPION. The labeled cells (FA-SPION and unconjugated SPION) were detached from the well using a trypsin/EDTA solution and harvested by centrifugation at $3000 \mathrm{rpm}$ for 5 minutes. The cells were resuspended in a PBS solution containing $1 \%$ paraformaldehyde followed by incubation at $4^{\circ} \mathrm{C}$ for 2 hours. The cells were subsequently washed with PBS solution and again harvested at $3000 \mathrm{rpm}$ for $3 \mathrm{~min}-$ utes and finally counted with a hemocytometer. Thereafter, the cells were transferred in $1.5 \mathrm{~mL}$ of microcentrifuge tubes at fixed number $(\sim 50,000$ cells per tube) for each concentration of FA conjugated SPION and unconjugated SPION.

All the MRI experiments were performed using a BrukerBiospec 4.7 T MRI scanner (BrukerBioSpin Corporation, Billerica, MA) within a $72 \mathrm{~mm}$ transmit/receive coil with a homogeneous B1 field to obtain the MR images and the rest of the parameters used in the experiment were similar as used by Jain et al. ${ }^{31}$

\section{Statistical analysis}

Statistical analyses were performed using the Student's $t$-test for unpaired data, and $P$ values of 0.05 were considered statistically significant. Data are presented as means \pm standard error of the mean.

\section{Results and discussion Synthesis and characterization of hydrophobic SPIONs}

Before one can utilize magnetic nanocrystals for biomedical applications, the utmost requirement is to develop welldefined magnetic nanocrystals. The key requirement for this model system is the fabrication of high-quality magnetic nanocrystals in terms of the size, crystalline phase, and stoichiometry, as these characteristics can affect the properties of SPIONs. ${ }^{13-15}$ In the present study, we synthesized magnetic nanocrystals through the thermal decomposition method in organic solvent to get high quality nanocrystals. TEM images demonstrated that the monodisperse SPIONs were formed in organic solvent (Figure 1A). The crystal structure information from an assembly of $\mathrm{Fe}_{3} \mathrm{O}_{4}$ nanoparticles was also obtained from both X-ray diffraction (XRD) and selected area electron diffraction (Figure 1B and C). The peaks were labeled with the indexed Bragg reflections of the magnetite structure and the particles were found to be highly crystalline. Using the Debye-Scherrer formula, the average size of the crystallite was determined to be $10 \mathrm{~nm}$, which was in good agreement with the average diameter of $8-10 \mathrm{~nm}$ measured from TEM images. These findings indicated that the particles were single crystalline. ${ }^{32}$ The selected area electron diffraction pattern taken from the area consisting of many particles represented $\mathrm{Fe}_{3} \mathrm{O}_{4}$ polycrystalline diffraction rings, in accordance with the XRD result. The magnetic properties of the SPIONs examined at room temperature by using a superconducting quantum interference device magnetometer indicated that the particles are super paramagnetic in nature. Furthermore, the net magnetization of the particle assemblies in the absence of an external field was zero. No hysteresis was seen when magnetization studies were performed on $10 \mathrm{~nm} \mathrm{Fe}_{3} \mathrm{O}_{4}$ nanoparticles at room temperature (Figure 1D). Under a large external field, the magnetization of the particles aligned with the field direction and reached its saturation value (saturation magnetization, $\sigma s)$. Fourier-transform infrared (FTIR) spectra of SPION were recorded to confirm the presence of a coating layer consisting of oleic acid on the surface of the nanoparticles (data not shown). The FTIR spectrum of oleic acid showed strong characteristic peaks, assigned to the $\mathrm{CH}_{2}$ asymmetric and symmetric stretching at $2893 \mathrm{~cm}^{-1}, 2841 \mathrm{~cm}^{-1}$, and scissoring at $1460 \mathrm{~cm}^{-1}$. A peak corresponding to the $\mathrm{C}=\mathrm{O}$ asymmetric stretching of ester of oleic acid around $1720 \mathrm{~cm}^{-1}$ was observed in iron oxide nanoparticles capped with oleic acid, which confirmed the capping of iron oxide nanoparticles by oleic acid.

\section{Generation and characterization of SPIONs suitable for biomedical applications by ligand exchange}

To make the SPION's suitable for biomedical application, SPIONs are synthesized in aqueous media wherein nanoparticles coated with hydrophilic dextran ${ }^{11}$ or polyvinyl alcohol..$^{33}$ But this process leads to large size and is limited in its ability to get uniform and monodispersed nanoparticles. SPIONs synthesized in organic solvent are highly hydrophobic and 
A

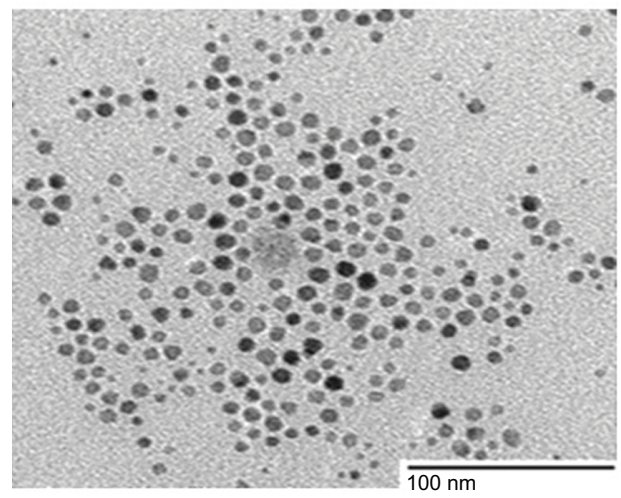

C

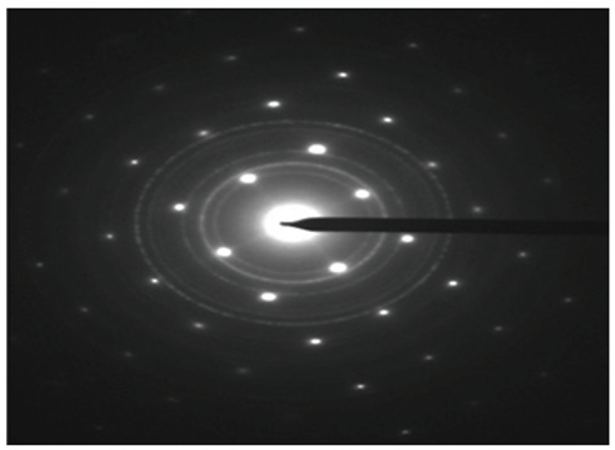

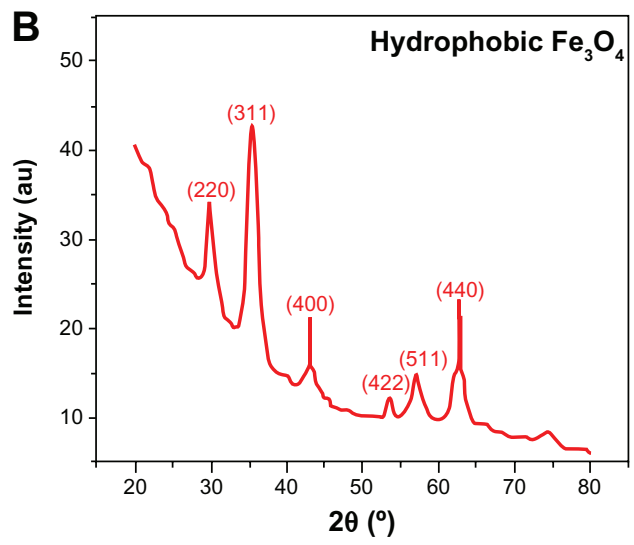

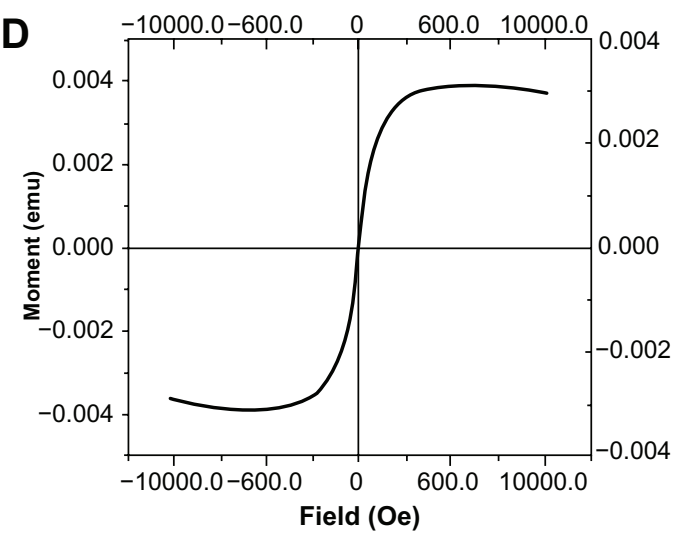

Figure I Characterization of hydrophobic SPIONs. (A) TEM (B) XRD (C) SAED pattern (D) SQUID.

Abbreviations: TEM, transmission electron micrograph; XRD, X-ray diffraction; SAED, single area electron diffraction pattern; SQUID, superconducting quantum interference device.

do not disperse well in water and thus cannot be used for biological application. Hydrophobic SPION's were subjected to ligand exchanges to produce hydrophilic SPIONs. The ligand exchange process was carried out at different temperatures for different ligands with continuous stirring, wherein hydrophobic ligand was exchanged by hydrophilic ligand. We carried out ligand exchange reactions with four different ligands: TMAOH at $30^{\circ} \mathrm{C}$, DMSA at $60^{\circ} \mathrm{C}$, citric acid $\left(\mathrm{CA}, 90^{\circ} \mathrm{C}\right)$, and a combination of $\mathrm{CA} / 2$-Bromo2-methyl propionic acid (BMPA, $90^{\circ} \mathrm{C}$ ). TMAOH functionalized SPIONs were found to be aggregated as shown in TEM images (Figure 2). For DMSA capped SPIONs dispersion was unstable over a period of time as evident from TEM images (Figure 2). Citric acid functionalized SPION (Figure 2) showed better dispersion stability but over a period of time it settled at the bottom due to aggregation. To enhance the dispersion stability, a combination of CA/BMPA was used. CA/BMPA capped SPIONs showed excellent dispersion stability as shown by TEM images (Figure 2D), which clearly indicated that there was no aggregation of nanoparticles upon transfer from organic to aqueous phase. CA/BMPA capped SPIONs were also characterized by XRD which clearly indicated that there was no alteration in crystal structure after ligand exchange. The FTIR spectra of CA and CA/BMPA showed complete ligand exchange while TMAOH and DMSA still had residual $-\mathrm{CH}_{2}$ peaks indicating incomplete removal of oleic acid from the surface of the SPIONs. This could be the possible cause of aggregation in these two systems. After ligand exchange, it was observed that CA/BMPA-SPIONs were more stable as compared to citric acid capped SPIONs (CA-SPIONs). CA/BMPA-SPIONs were stable up to $250 \mathrm{mM} \mathrm{NaCl}$ solution and between $\mathrm{pH} 6$ to 10. However, these SPIONs were aggregated below $\mathrm{pH}$ 6.0. Furthermore, CA-SPIONs were found to have stable dispersion in PBS (pH 7.4) up to 4-5 weeks while CA/BMPA-SPIONs were stable for 2 years as confirmed by TEM and dynamic light scattering (Figures 10A and B). CA/BMPA showed better dispersion stability of SPIONs for a longer period of time. Hence, all further studies were performed using CA/BMPASPIONs unless otherwise stated. CA/BMPA-SPIONs were successfully conjugated to FA using EDC/NHS chemistry. Excess FA was removed by thoroughly washing the sample 

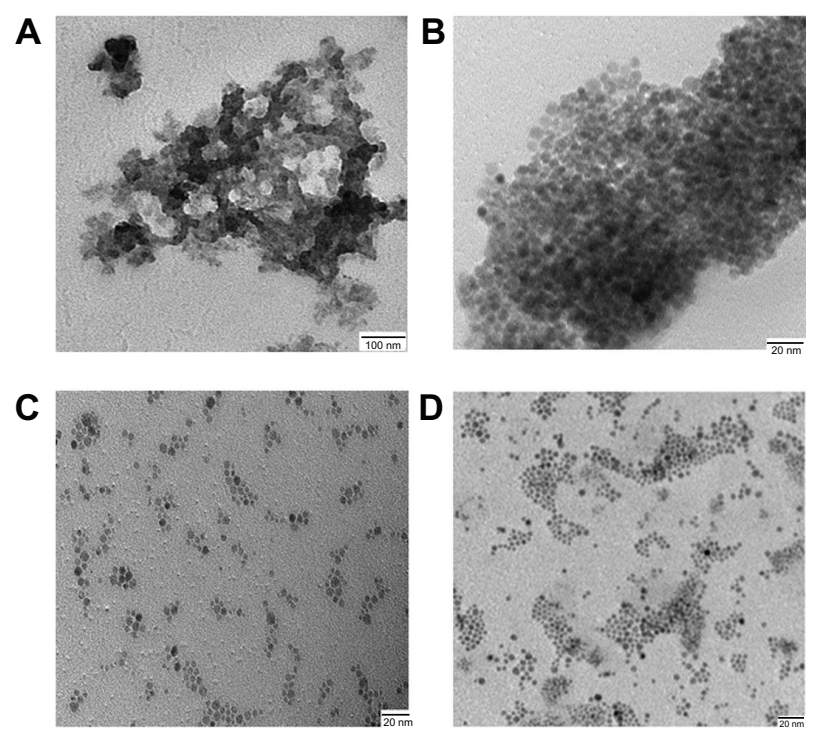

Figure 2 TEM micrograph of hydrophilic SPION coated with different ligands (A) TMAOH (B) DMSA (C) CA (D) CA/BMPA.

Abbreviations: TEM, transmission electron microscopy; SPION, superparamagnetic iron oxide nanoparticles; TMAOH, tetramethyl ammonium hydroxide; DMSA, dimercaptosuccinic acid; CA, citric acid; BMPA, 2-Bromo2-methyl propionic acid. with PBS (pH 7.4). Attenuated total reflectance-FTIR spectroscopy was performed to confirm the conjugation of FA with SPIONs. The results demonstrated additional peaks at $1645 \mathrm{~cm}^{-1}$ and $1566 \mathrm{~cm}^{-1}$ in FA-conjugated SPIONs but the additional peaks were absent in unconjugated SPIONs, which indicate the $-\mathrm{C}=\mathrm{O}$ stretch in FA-SPION due to $-\mathrm{COOH}$ group (data not shown). The smaller size of the ligands in our nanocrystals is extremely advantageous in physiological conditions. Retaining the small probe size has been shown to be critical for successful in vivo applications since large-sized probes significantly reduce their bio-stability, diffusion, and circulation processes. ${ }^{14}$ Large size probes were shown to increase undesired nonspecific binding and reticuloendothelial system uptake. ${ }^{34}$ Moreover, small sized probes can be potentially useful for enhanced biological targeting efficiency and specificity. ${ }^{35}$ Since the folate-receptor (FAR) is over expressed in multiple tumor types, ${ }^{22-24}$ specific targeting of the nanoparticles with FA would be potentially useful for biological functions.

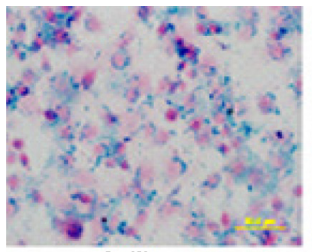

A (i)

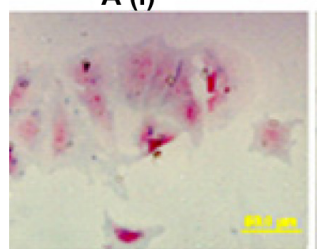

B (i)

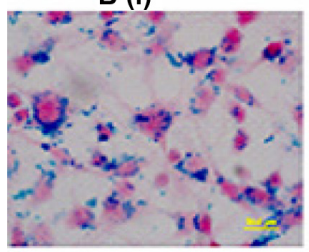

C (i)

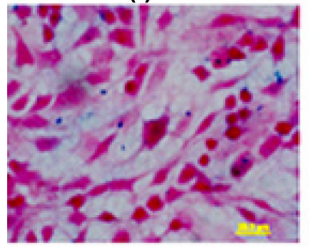

D (i)

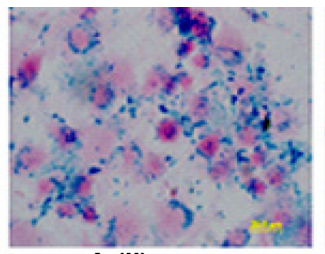

A (ii)

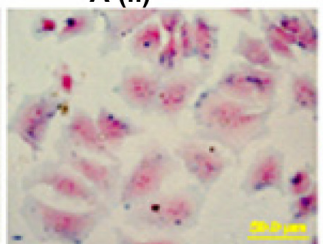

B (ii)

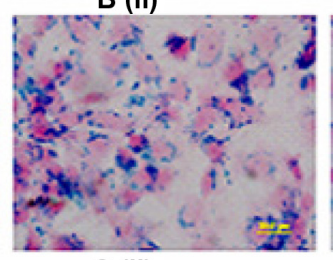

C (ii)

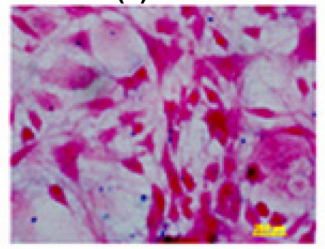

D (ii)

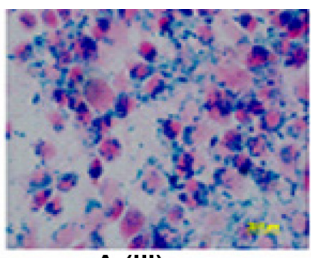

A (iii)

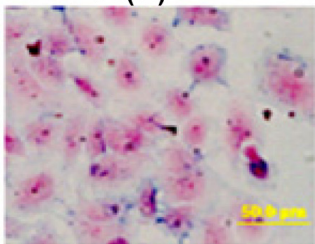

B (iii)

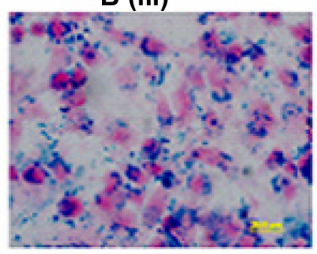

C (iii)

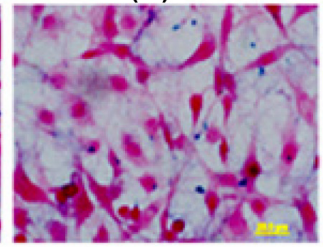

D (iii)

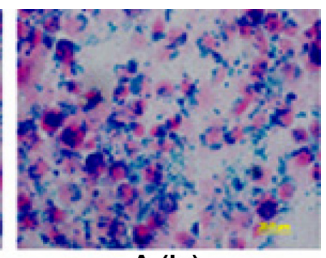

A (iv)
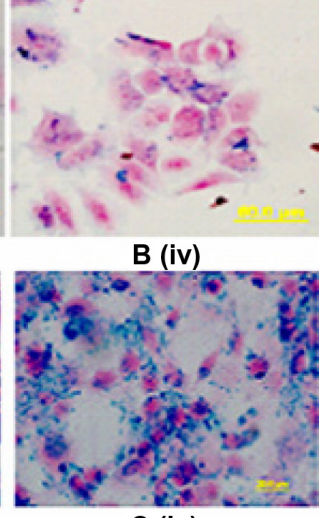

C (iv)

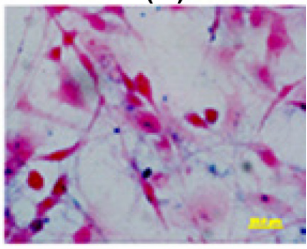

D (iv)

Figure 3 Prussian blue histochemical reaction of MCF-7 and HepG2 cells following incubation with different concentrations (25-200 $\mu g / m L)$ of FA-SPION and SPION. A(i-iv) MCF-7 with different concentrations of FA-SPION B(i-iv) MCF-7 with different concentrations of unconjugated SPION. C(i-iv) HepG2 with different concentrations of FA-SPION D(i-iv) HepG2 with different concentrations of unconjugated SPION.

Abbrevations: MCF-7, hormone dependent breast carcinoma cells; HepG2, Hepato-carcinoma cells; FA-SPIONs, folic acid conjugated superparmagnetic iron oxide nanoparticles; SPION, superparamagnetic iron oxide nanoparticles. 


\section{Uptake of FA-conjugated SPIONs in FAR overexpressing tumor cells}

\section{Prussian blue staining}

Earlier studies have shown that FAR is overexpressed in multiple tumor types. ${ }^{22-24}$ We generated SPIONs that were conjugated with FA for tumor specific uptake and characterized them for appropriate biomedical applications. To demonstrate uptake of FA-conjugated SPIONs by FAR-positive tumor cells, further experiments were performed in hormone-dependent breast carcinoma cells, MCF-7 cells, and hepato-carcinoma cells HepG2. As a control, uptake of FA-conjugated SPIONs was also studied in FAR-negative cell lines, such as non-small cell lung carcinoma, A549. The results demonstrated that there was a clear increase of intracellular iron, as visualized by blue granules in Prussian blue staining of MCF-7 cells (Figures 3A and B). Similar results were obtained when the HepG2 cell line was used (Figure $3 \mathrm{C}$ and D). Additionally, we also compared the uptake of FA-conjugated verses unconjugated SPIONs in MCF-7 and HepG2 cells. In this regard, by contrast to unconjugated SPIONs, the uptake of FA-conjugated SPIONs by MCF-7 and HepG2 cells was significantly increased (Figure 3A and D). Histological analysis of MCF-7 and HepG2 cells demonstrated significant reduction in blue granules by cells treated with unconjugated SPIONs. While the increase in intracellular unconjugated SPION granules was somewhat visible, however, the staining was considerably less intense as compared to that with the FA-conjugated SPIONs. Furthermore, substantially less staining was observed when FAR-negative A549 cells were treated with FAconjugated SPIONs (data not shown). Taken together, these findings indicated that conjugating the SPIONs with a tumor targeting agent, FA specifically, increased targeting and internalization of SPIONs in tumor cells.

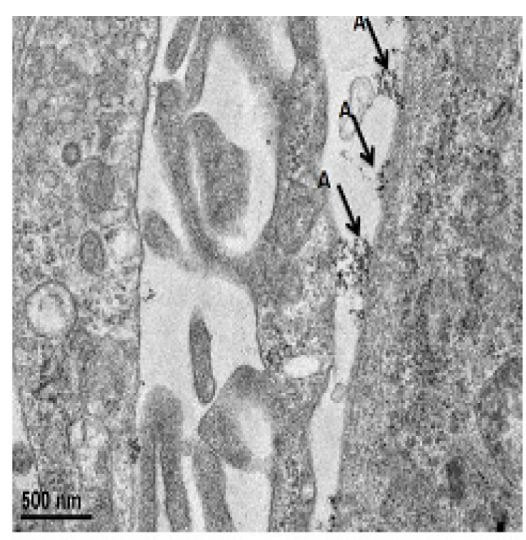

I

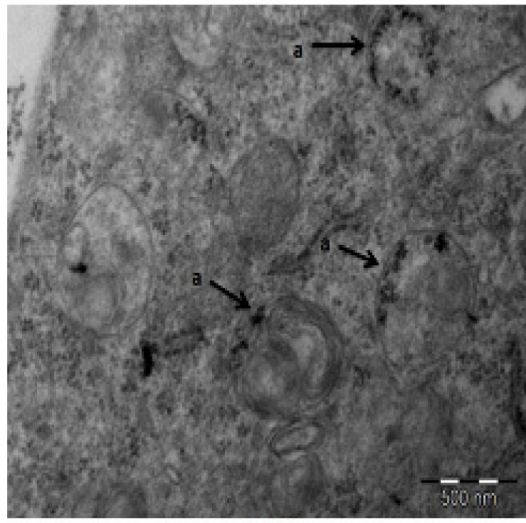

IV

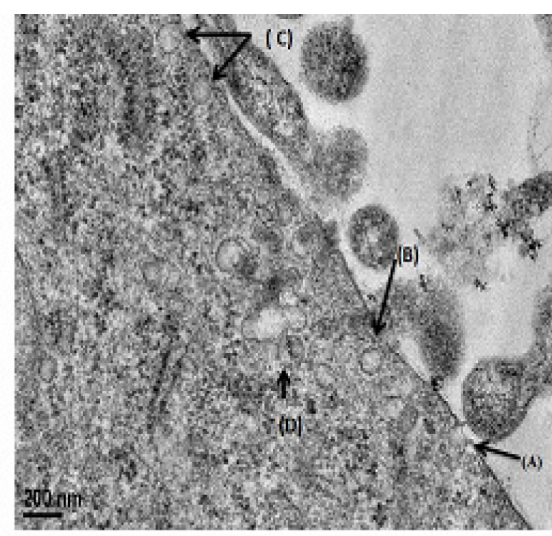

II

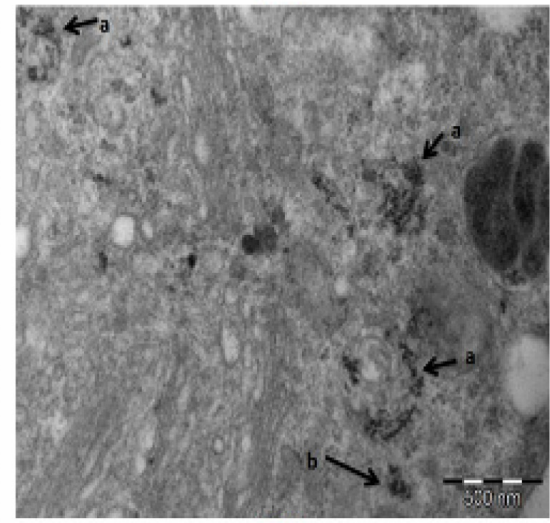

V

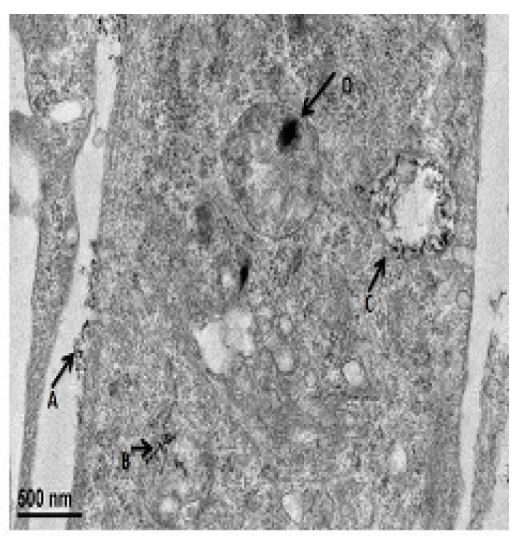

III

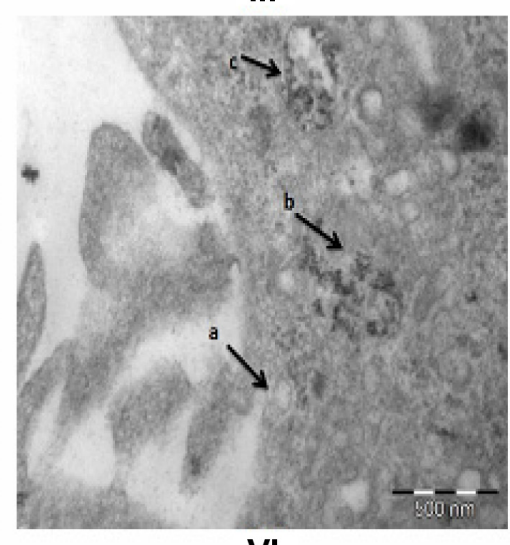

VI

Figure 4 TEM Studies of interaction of FA-SPION with MCF-7 cells. (I) (A) Attachment of FA-SPION on the cell membrane of MCF-7. (II) (A) Pit formation started (B) Clathrin Pit almost completed (C) multiple pits on the membrane (D) SPION inside the lysosome and start of coalescing of multiple vesicles. (III) (A) SPION in the pit (B) SPION inside the lysosome (C) Multi vesicular body (MVB) filled with SPION (D) aggregated SPION inside the mature lysosomes. (IV) (a) SPIONs inside the different stages of lysosomes. (V) (a) Aggregation of SPION in lysosomes (b) SPION in the cytoplasm (outside lysosomes). (VI) (a) clathrin pit (b) ruptured MVB's with SPIONS (possible entry of SPIONs to cytoplasm) (c) Multi Vesicular Body (MVB's).

Abbreviations: MCF-7, hormone dependent breast carcinoma cells; FA-SPIONs, Folic acid conjugated superparamagnetic iron oxide nanoparticles; MVB's, multi vesicular bodies; FA-SPIONs, folic acid conjugated superparmagnetic iron oxide nanoparticles; SPION, superparamagnetic iron oxide nanoparticles. 

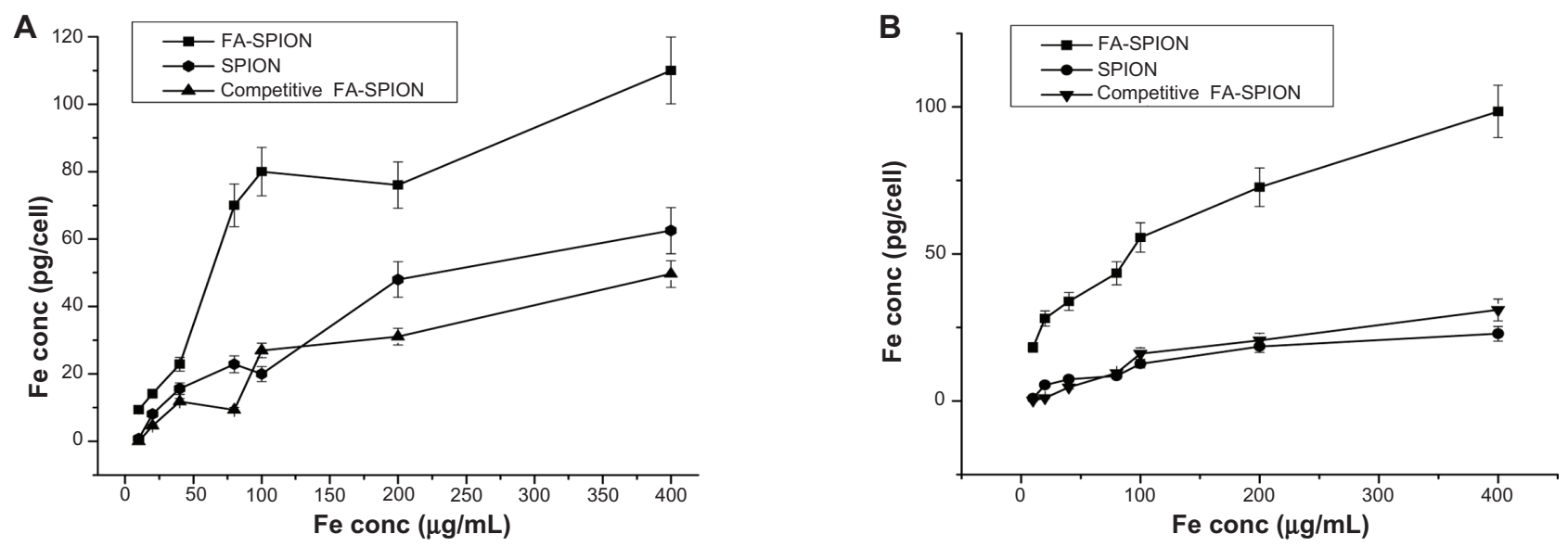

C

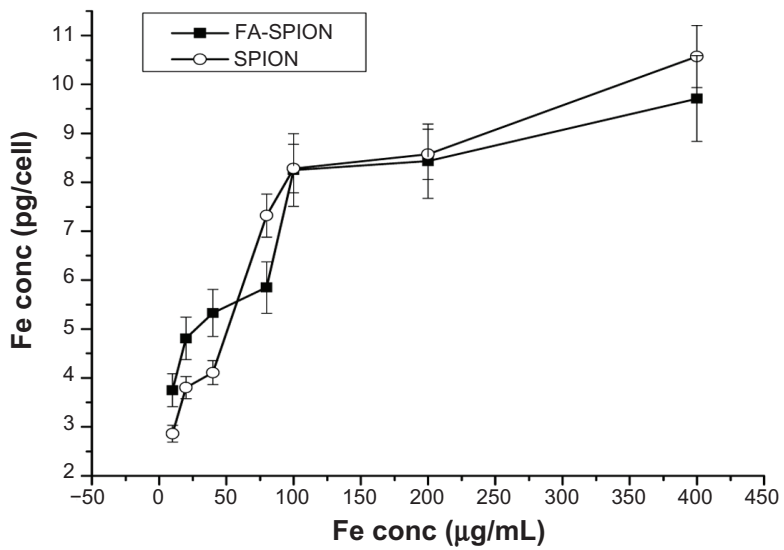

Figure 5 Intracellular Fe concentration in MCF-7, HepG2 and A549. Iron concentration in MCF-7 (A), HepG2 (B) FAR positive and A549 (C) FAR negative cells that were treated with different concentrations ranging from $10 \mu \mathrm{g} / \mathrm{mL}-400 \mu \mathrm{g} / \mathrm{mL}$ of FA-SPION, SPION and competitive inhibition by FA (I0 mM) of competitive FA-SPION for $6 \mathrm{hrs}$. Abbreviations: FAR, folic acid receptor;FA, folic acid; MCF-7, hormone dependent breast carcinoma cells; HepG2, Hepato-carcinoma cells; A549, non-small cell lung carcinoma cells;FA-SPIONs, folic acid conjugated superparmagnetic iron oxide nanoparticles; SPION, superparamagnetic iron oxide nanoparticles.

\section{TEM studies}

FA-specific tumor targeting and internalization of FAconjugated SPIONs was further confirmed using TEM analysis. Earlier studies have indicated that the uptake of nanoparticles is mediated via endocytosis. ${ }^{36}$ Endocytosis is considered to be the prime mechanism for the uptake of $<150 \mathrm{~nm}$ sized extracellular materials. Moreover, clathrin coated pits, the prime plasma membrane components, are shown to be involved in the uptake of a wide variety of molecules by receptor-mediated endocytosis. ${ }^{37,38}$ To define internalization and cellular trafficking of SPIONs, MCF-7 cells were treated with FA-conjugated SPIONs and followed for different time intervals and analyzed by TEM. FA-conjugated SPIONs were initially seen on the MCF-7 cell membranes demonstrating interactions of FA with its receptors before internalization into the cells (Figure 4). At different time points, internalized FA-SPIONs were localized throughout the endocytic- degradative pathways (ie, endocytic vesicles, endosomal compartment, and lysosome). Endosomes appeared as electron lucent multivescicular bodies with varying numbers of internal vesicles, probably representing the transition from early to late endosome (Figure 4). We also observed numerous enlarged endosomes in which FA-conjugated SPIONs were accumulated. Moreover, FA-conjugated SPIONs were also seen in the cytosol. This study also indicated that other cellular organelles did not show any structural abnormality by accumulation of SPIONs. Taken together, the results indicated that the internalization of nanoparticles is dependent on the nature of the nanoparticle, incubation time, and the targeting molecule. These findings further indicate that the possible mechanism of uptake of FA-conjugated SPIONs, at least in part, is via receptor-mediated endocytosis. However, further in-depth studies are needed to clearly define the mechanism of internalization of FA-conjugated SPIONs in tumor cells. 

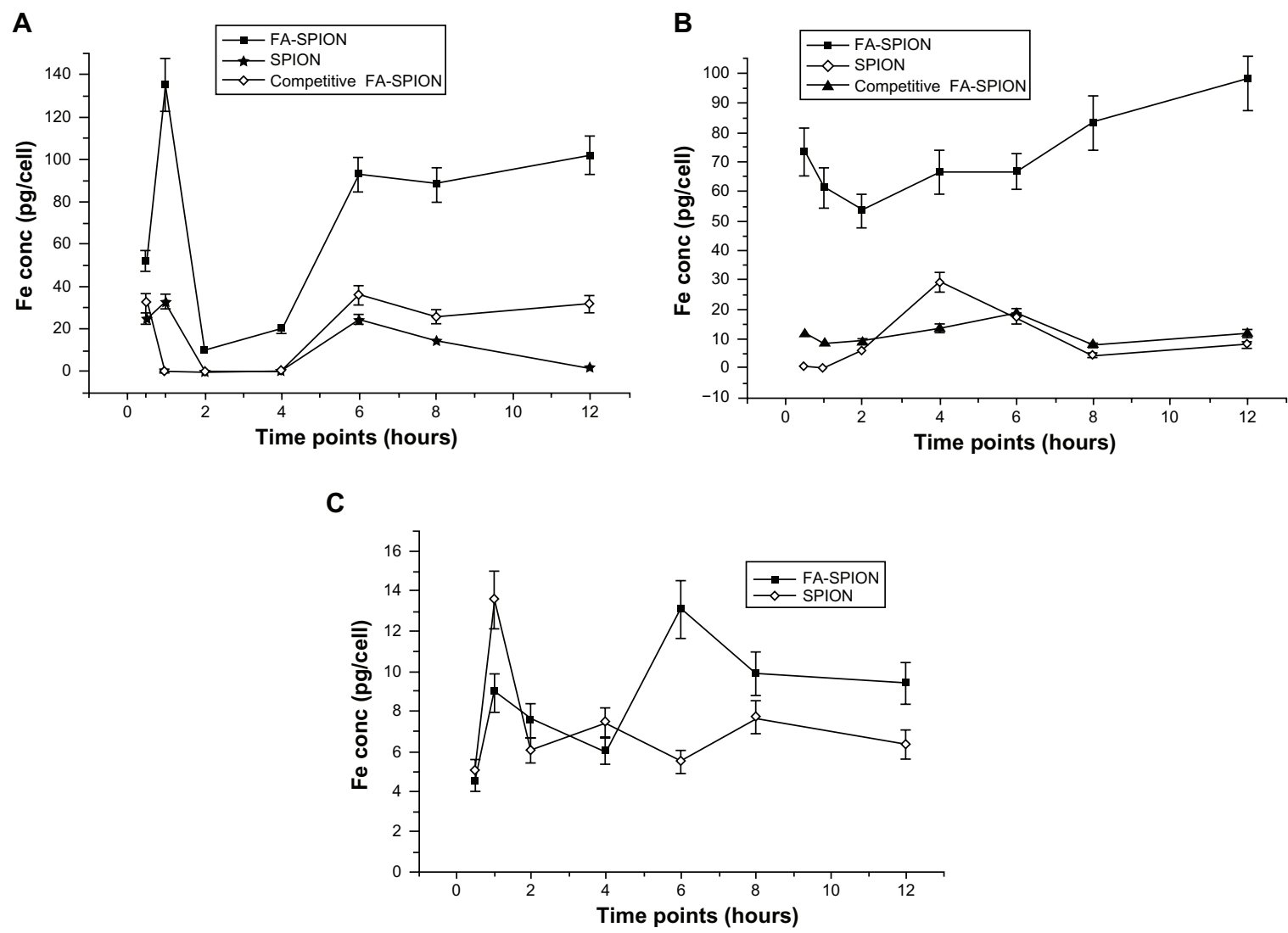

Figure 6 Intracellular Fe concentration in different cell lines. Fe concentration in MCF-7 (A), HepG2 (B) FAR positive and A549 (C) FAR negative cells that were treated with $100 \mu \mathrm{g} / \mathrm{mL}$ concentration of FA-SPION, SPION and competitive inhibition by FA ( $10 \mathrm{mM}$ ) of competitive FA-SPION for different period of time ranging from 30 minutes to 12 hours.

Abbreviations: FAR, folic acid receptor; FA, folic acid; MCF-7, hormone dependent breast carcinoma cells; HepG2, Hepato-carcinoma cells; A549, non-small cell lung carcinoma cells; FA-SPIONs, folic acid conjugated superparmagnetic iron oxide nanoparticles; SPION, superparamagnetic iron oxide nanoparticles.

\section{XTT assays}

To assess any potential cytotoxicity of these FA-conjugated SPIONs on cells, further studies were performed using MCF-7 and HepG2 cells. These cell lines were treated with different concentrations of FA-SPIONs for 24 or 48 hours and analyzed by XTT assays for cell viability. The results demonstrated no toxicity of FA-conjugated SPIONs, even at the highest concentration tested (Figure 9A and B).

\section{Concentration dependent cellular uptake studies}

Earlier studies have shown that iron oxide nanoparticles biodegrade in lysosomes over a period of time. ${ }^{18}$ In this context, the FA-conjugated SPIONs described in the present study could be useful in multiple biomedical applications. To further define the practical implications of FA-conjugated SPION-cell interaction, we next studied the potency of cellular uptake of these nanoparticles. The detailed cellular uptake studies were conducted as a function of concentration and time. These cellular iron quantification studies were performed using FAR-positive (MCF-7, HepG2) and (A549) tumor cell lines. Investigations were also carried out to define the role of FA as a targeting agent and the surface coating efficacy on internalization of SPIONs. The results demonstrated that the Fe content per cell, as determined by AAS, significantly varied among different cell types (Figure 5). We found an accumulation of iron oxide in MCF-7 cells with the mean iron content ranges from $9.37+0.8$ to $110+9.9 \mathrm{pg} \mathrm{Fe} / \mathrm{cell}$ (Figure 5A). HepG2 cells also showed an intense uptake of FA-SPION, reaching an intracellular iron oxide concentration range of $18.18+1.6$ to $98.48+6.81 \mathrm{pg} \mathrm{Fe} /$ cell (Figure 5B) Moreover, in concert with the results shown above, the uptake of FA-conjugated SPIONs is significantly higher than that of non-conjugated SPIONs. The accumulated iron oxide concentration range for MCF-7 and HepG2 cells treated with non-conjugated SPIONs was $0.83+0.9$ to $62.5+6.9 \mathrm{pg} \mathrm{Fe} /$ cell and $0.91+1.01$ to $22.85+2.5 \mathrm{pg} \mathrm{Fe} /$ cell respectively. In comparison, MCF-7 and HepG2 cell uptake of FA-conjugated SPIONs was $2-15$ times higher than that obtained with nonconjugated SPIONs at different concentrations. To further define the targeting specificity of FA-SPIONs, uptake studies 
A
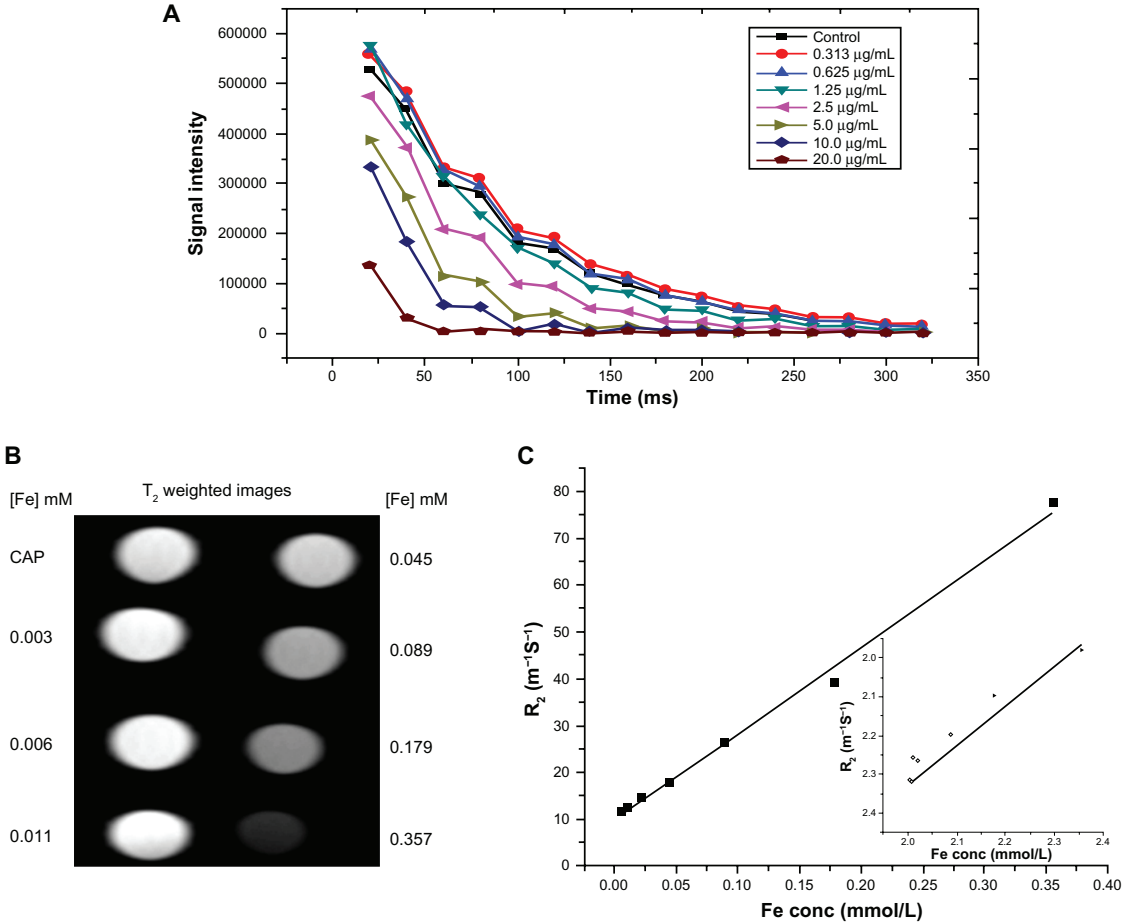

Figure 7 Magnetic resonance imaging properties of FA-SPIONs: (A) signal intensity weighted images (TR I/4 I0,000 ms, TE I/4 I0 ms) of FA-SPIONs in phantom agar gel at various iron concentrations at $25^{\circ} \mathrm{C}$, blank phantom agar gel was taken as a control (data as mean intensity within region of interest (ROI)); (B) $T_{2}$-weighted $M R$ images of FA-SPION in phantom gel with various concentrations at $4.7 \mathrm{~T}$. (C) Graphs of $R_{2}\left(R_{1}\right.$ inset) against the iron concentration in FA-SPION.

Abbreviations: TR, repetition time; TE, echo time; $T_{2}$, transverse relaxation time; $R_{2}$, transverse relaxation rate; $R_{1}$, longitudinal relaxation rate; $R O I$, region of interest; FA-SPIONs, folic acid conjugated superparmagnetic iron oxide nanoparticles.
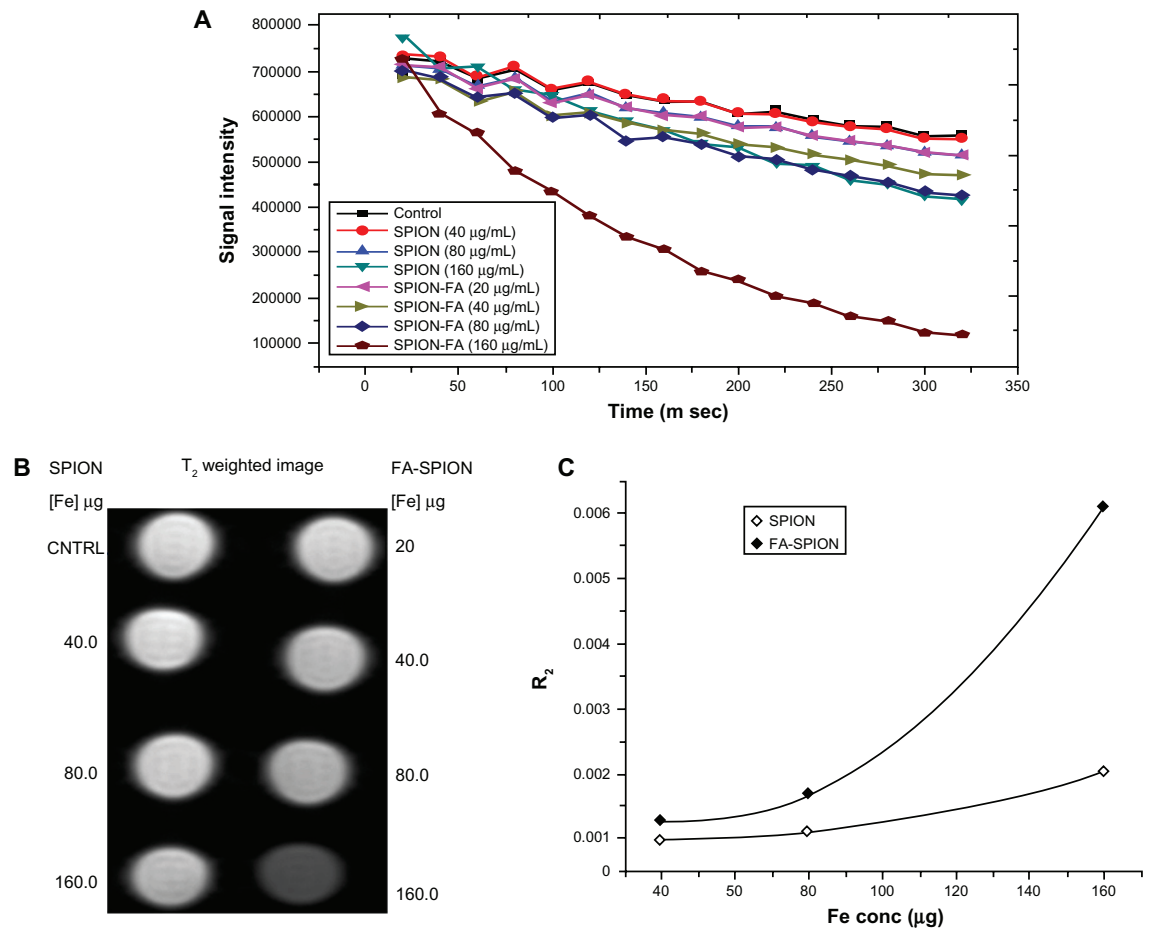

Figure 8 Magnetic resonance imaging properties of MCF-7 cells labeled with SPIONs: (A) signal intensity weighted images (TR I/4 10,000 ms, TE I/4 10 ms) of MCF-7 cells labeled FA-SPIONs and SPIONs in DMEM media at various iron concentrations at $25^{\circ} \mathrm{C}$, blank phantom agar gel was taken as a control (data as mean intensity within region of interest (ROI)); (B) $\mathrm{T}_{2}$-weighted MR images of MCF-7 cancer cells treated with different concentrations FA-SPION and SPION (C) Graph of $R_{2}$ of MCF-7 cancer cells treated with different concentrations FA-SPION and SPION.

Abbreviations: TR, repetition time; TE,echo time; $T_{2}$, transverse relaxaxtion time; $R_{2}$, transverse relaxation rate; $R O I$, region of interest; $M C F-7$, hormone-dependent breast carcinoma cells; FA-SPIONs, folic acid conjugated superparmagnetic iron oxide nanoparticles; SPION, superparamagnetic iron oxide nanoparticles. 

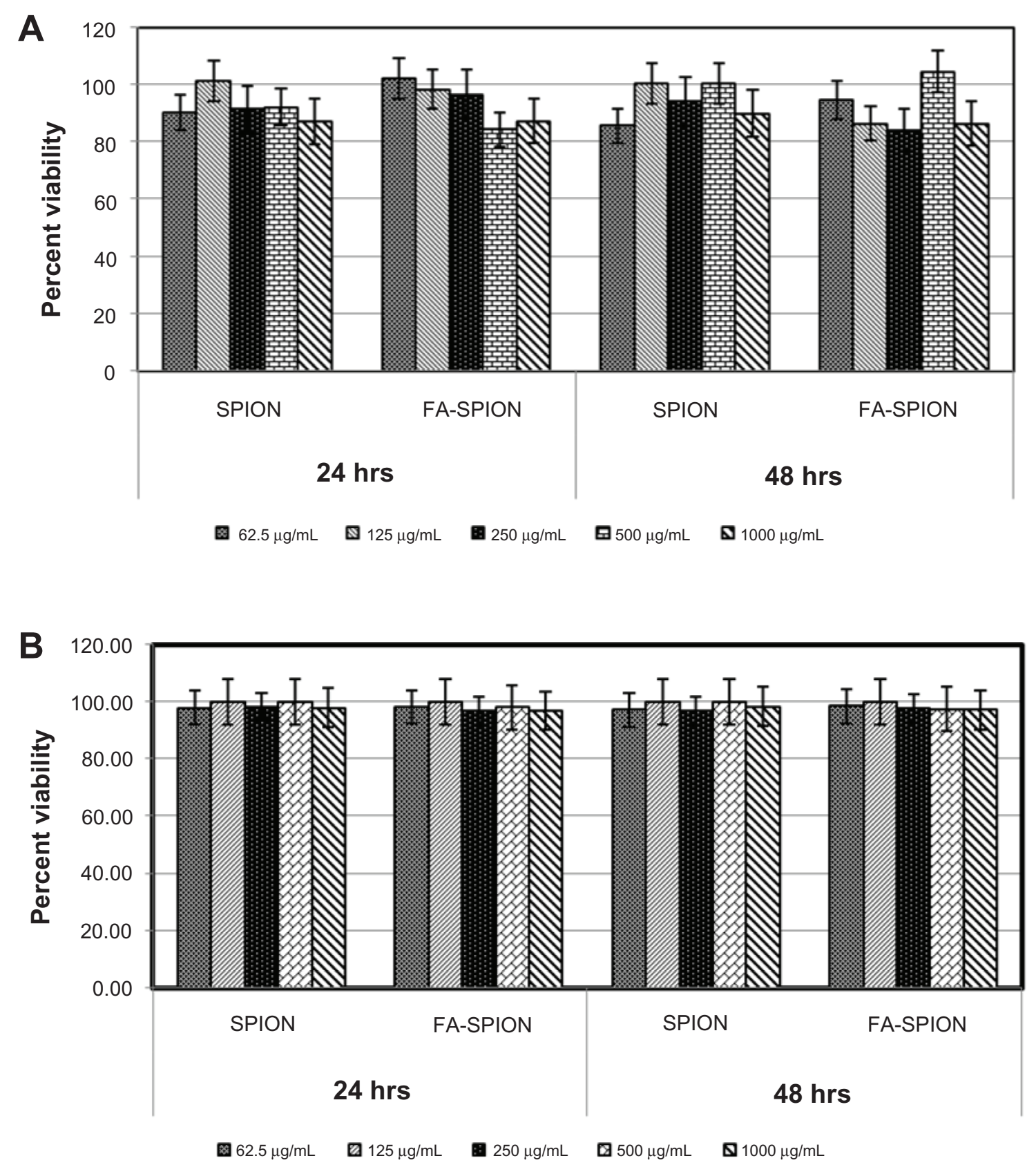

Figure 9 Cytotoxicity (XTT assay) to cells exposed to different concentrations $(62.5-1000 \mu \mathrm{g} / \mathrm{mL})$ of FA-SPION and SPION for different time points 24 and 48 hours. (A) MCF-7 cells; (B) HepG2 cells.

Abbreviations: XTT, (2,3-Bis-(2-Methoxy-4-Nitro-5-Sulfophenyl)-2H-Tetrazolium-5-Carboxanilide); FA-SPION, folic acid conjugated superparamagnetic iron oxide nanoparticles; SPION, superparamagnetic iron oxide nanoparticles; MCF-7, hormone dependent breast carcinoma cells; HepG2, Hepato-carcinoma cells.

of FA-SPIONs were compared between FAR-positive and FAR-negative tumor cell lines. The results demonstrated that uptake of FA-SPIONs by HepG2 or MCF-7 cells was 10-12 times more than that compared with A549 (Figure 5C). The increased uptake by A549 cells at higher concentrations of nanoparticles is likely due to increased availability of the nanoparticles and internalization through nonspecific mechanisms. In this regard, the results from our present study are in agreement with the previously published findings regarding the uptake of non-conjugated SPIONs at very high concentrations. ${ }^{39-42}$

To further assess the competitive and specific uptake of FA-conjugated CA/BMPA-SPIONs, we treated MCF-7 or HepG2 cells with FA-SPIONs in the presence or absence of free FA in molar excess. The results demonstrate that the uptake of FA-SPIONs by MCF-7 cells was significantly decreased when the cells were grown in the presence of an excess amount of free FA (Figure 5A). Similar 


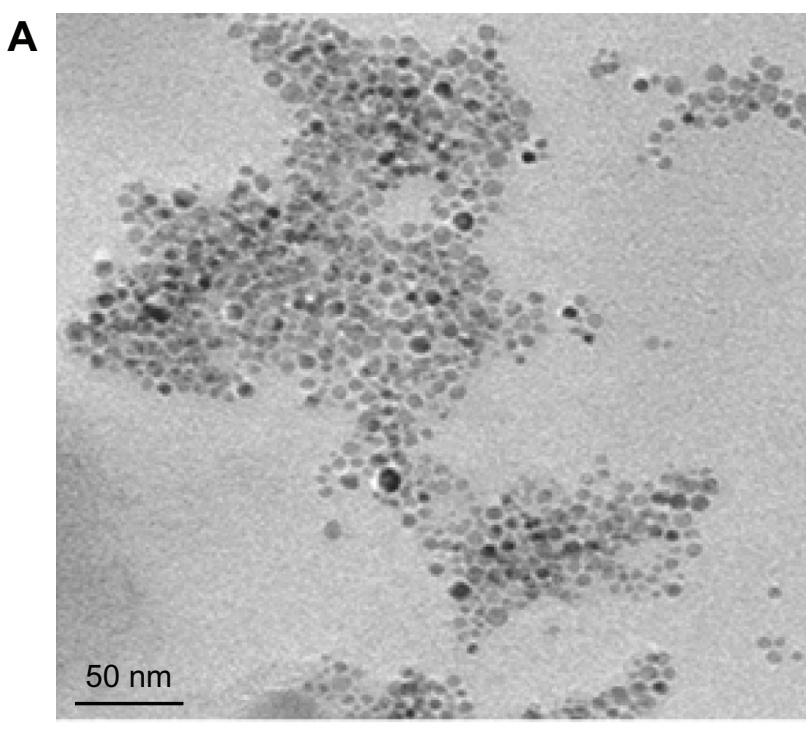

B

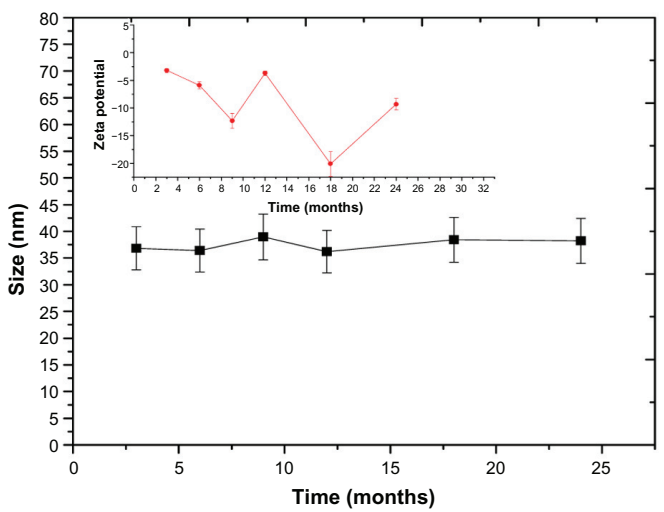

Figure 10 Long term stability study CA/BMPA capped SPION in PBS solution $\mathrm{pH}$ 7.4. (A) TEM micrograph (B) DLS data.

Abbreviations: CA/BMPA, citric acid/2-bromo-2-methylpropionic acid; SPION, superparamagnetic iron oxide nanoparticles; PBS, phosphate buffer saline; DLS, dynamic light scattering.

results were obtained in HepG2 cells (Figure 5B). These findings strongly demonstrated that free FA competed with the FA-SPIONs for uptake by the cells and thereby confirmed that FA-SPIONs were specifically targeted at folate receptors.

\section{Time dependent cellular uptake studies}

Additional studies were carried out to determine the internalization kinetics of FA-conjugated and non-conjugated SPIONs into MCF-7 and HepG2 cells at different time intervals. In these studies, MCF-7 cells were treated with $100 \mu \mathrm{g}$ of FAconjugated or non-conjugated SPIONs and internalization kinetics were studied over a period of time. Figure 6A shows the internalization kinetics of conjugated and unconjugated SPIONs in MCF-7 cells. The results convincingly indicated that the uptake of FA-conjugated SPIONs was much higher compared to non-conjugated SPIONs (Figure 6A). However, internalization of FA-conjugated SPIONs over a period of time was not uniform. A unique pattern was observed in the uptake of FA-conjugated SPIONs by MCF-7 cells. Initially there was an increase in SPIONs concentration $(134+12.14$ $\mathrm{pg} \mathrm{Fe} / \mathrm{cell})$ followed by a decline at 2 to 4 hours $(\sim 10-20 \mathrm{pg}$ $\mathrm{Fe} / \mathrm{cell})$ and then again a sharp increase to $92.67+8.34 \mathrm{pg} \mathrm{Fe} /$ cell by 6 hours which was maintained through long intervals (Figure 6A). Similarly, HepG2 cells have also shown higher uptake at 30 minutes followed by a small decline at 2 hours and finally reached to a concentration of $75.75+9.17 \mathrm{pg} \mathrm{Fe} /$ cell (Figure 6B). In comparison to unconjugated SPIONs, the FA-conjugated SPIONs showed a prolonged retention of internalized nanoparticles, which may be helpful for MRI detection of FA receptor expressing cells. The initial decline in the uptake of FA-conjugated SPIONs observed in this study may in part be explained by the probable phenomenon of exocytosis. Nanoparticle endocytosis and exocytosis are dynamic and energy-dependent processes, which are proceeding simultaneously in eukaryotic cells. ${ }^{43-45}$

\section{MRI characteristics of magnetic nanoparticles in phantom agar gel and MCF-7 cells}

The $\mathrm{T}_{1}$ and $\mathrm{T}_{2}$-weighted MRI of FA-SPIONs in water was examined at $4.7 \mathrm{~T}$ using various concentrations in phantom gel and MCF-7 cells. The results demonstrated that as the SPION concentration was increased, the signal intensity of spin-spin relaxation time $T_{2}$-weighted MRI image decreased. The $T_{2}$ and $T_{1}$ relaxivity coefficient $\left(R_{2}\right.$ and $R_{1}$ values), which are the measures of the spin-spin relaxation rate $\left(\mathrm{T}_{2}^{-1}\right)$ and spin lattice relaxation rate $\left(\mathrm{T}_{1}^{-1}\right)$ per unit Fe concentration, were calculated at $4.7 \mathrm{~T}$ to be $222 \mathrm{~L} \mathrm{mmol}^{-1} \mathrm{sec}^{-1}$ and $4.11 \mathrm{~L} \mathrm{mmol}^{-1} \mathrm{sec}^{-1}$, respectively (Figure $7 \mathrm{C}\left(\mathrm{R}_{1}\right.$ Inset graph)). For the commercial products, Feridex and Resovist, the $\mathrm{R}_{2}$ values were $105 \mathrm{~L}$ $\mathrm{mmol}^{-1} \mathrm{sec}^{-1}$ and $176 \mathrm{~L} \mathrm{mmol}^{-1} \mathrm{sec}^{-1}$, respectively, and the $\mathrm{R}_{1}$ values were $2.3 \mathrm{~L} \mathrm{mmol}^{-1} \mathrm{sec}^{-1}$ and $2.8 \mathrm{~L} \mathrm{mmol}^{-1} \mathrm{sec}^{-1}$, respectively, at $4.7 \mathrm{~T}^{46}{ }^{46}$ Therefore, the $\mathrm{R}_{2}$ of FA-SPIONs was higher and the $\mathrm{R}_{1}$ of FA-SPIONs was almost equivalent to those of commercial products, respectively. It is well known that the relaxivity ratio, $R_{2} / R_{1}$, is usually an important parameter to estimate the efficiency of negative contrast agents. In our work $R_{2} / R_{1}$ was calculated to be 54 , which was higher than Feridex and a little less than Resovist coated with higher molecular weight ligands. Figure $8 \mathrm{~B}$ shows $\mathrm{T}_{2}$-weighted $\mathrm{MR}$ images in untreated MCF-7 cells or treated with FA-conjugated-SPION at three different $\mathrm{Fe}$ concentrations. Results were also compared to that with MCF-7 cells treated with unconjugated SPIONs. The results demonstrate that $\mathrm{T}_{2}$-weighted MR images 
of FA-SPION treated MCF-7 cells were darker than those of either the unconjugated SPION or the untreated control at all the Fe concentrations used in this study (Figure 8B). $\mathrm{T}_{2}$ relaxation time of the FA-SPION- treated cells decreased from 777.78 to $163.66 \mathrm{~ms}^{-1}$ in comparison to non-conjugated SPION which showed a decrease from 1015.13 to $493 \mathrm{~ms}^{-1}$ at Fe concentrations ranging from $40 \mu \mathrm{g} \mathrm{Fe} / \mathrm{mL}$ to $160 \mu \mathrm{g}$ $\mathrm{Fe} / \mathrm{mL}$. The $\mathrm{R}_{2}$ value of cells treated with FA-SPION was higher as compared to nonconjugated SPIONs (Figure 8C). As expected, the FA conjugated SPIONs offered a specific targeting ability in MCF-7 cells that overexpress FAR.

\section{Conclusion}

FA conjugated, CA/BMPA capped iron oxide nanoparticles were synthesized and characterized for MR imaging of breast cancer MCF-7 cells. The hydrophilic SPIONs capped with CA/BMPA and conjugated with FA were found to be monodispersed, highly stable in PBS and have shown dispersion stability for more than 2 years as observed from dynamic light scattering and TEM studies. FA-SPIONs showed no cellular cytotoxicity and were expected to be completely degraded by enzymes present in physiological conditions. The cellular uptake of FA-SPIONs was mediated through FAR mediated endocytosis and a possible mechanism, at least in part, is a clathrin mediated pathway. As verified by Prussian blue staining, iron content and in vitro MR imaging, FA-SPIONs had better targeting tropism, showed better cellular internalization in FAR-positive MCF-7 and HepG2 cells and maintained for longer periods in these cells than did their non-targeted counterparts. The relaxivity of FA-SPIONs was much greater than that of the existing commercial products. $\mathrm{T}_{2}$-weighted images of MCF-7 breast cancer cells that overexpressed FAR showed significantly enhanced signal intensities. The high intracellular uptake of FA-conjugated SPIONs may help to detect the collection of a small number of cancer cells (early and mirometastasis) which is difficult to detect by conventional MRI imaging. Furthermore the excellent long term colloidal stability may enhance its translational potential. Therefore, the FA-SPIONs, possessing good colloidal stability and affording excellent sensitivity of imaging, are proposed as a potential MRI contrast agent for the detection of breast cancer and other cancer cells overexpressing the folate receptor.

\section{Acknowledgment}

The authors gratefully acknowledge Lockheed Martin Corporation (NJ, USA), Department of Science and Technology, Govt of India and Council of Scientific and Industrial Research for financial assistance and Supported
Accommodation Innovation Fund, SAIF, AIIMS for TEM studies.

\section{Disclosure}

The authors report no conflicts of interest in this work.

\section{References}

1. Laurent S, Forge D, Port M, et al. Magnetic iron oxide nanoparticles: synthesis, stabilization, vectorization, physicochemical characterizations, and biological applications. Chem Rev. 2008;108(6):2064-2110.

2. Bruns OT, Ittrich H, Peldschus K, et al. Real-time magnetic resonance imaging and quantification of lipoprotein metabolism in vivo using nanocrystals. Nat Nanotechnol. Mar 2009;4(3):193-201. Epub January 25, 2009.

3. Fang C, Zhang M. Multifunctional magnetic nanoparticles for medical imaging applications. J Mater Chem. 2009;19:6258-6266.

4. McCarthy JR, Weissleder R. Multifunctional magnetic nanoparticles for targeted imaging and therapy. Adv Drug Deliv Rev. August 17, 2008;60(11):1241-1251. Epub April 10, 2008.

5. Wang YX, Hussain SM, Krestin GP. Superparamagnetic iron oxide contrast agents: physicochemical characteristics and applications in MR imaging. Eur Radiol. 2001;11(11):2319-2331.

6. Bonnemain B. Superparamagnetic agents in magnetic resonance imaging: physicochemical characteristics and clinical applications. A review. J Drug Target. 1998;6(3):167-174.

7. Harisinghani MG, Barentsz J, Hahn PF, et al. Noninvasive detection of clinically occult lymph-node metastases in prostate cancer. $N$ Engl J Med. 2003;348(25):2491-2499.

8. Singh A, Patel T, Hertel J, Bernardo M, Kausz A, Brenner L. Safety of ferumoxytol in patients with anemia and CKD. Am J Kidney Dis. Nov 2008;52(5):907-915. Epub September 27, 2008.

9. Lee JH, Huh YM, Jun YW, et al. Artificially engineered magnetic nanoparticles for ultra-sensitive molecular imaging. Nat Med. Jan 2007;13(1):95-99. Epub December 24, 2006.

10. Goya GF, Grazú V, Ibarra MR. Magnetic nanoparticles for cancer therapy. Curr Nanosci. 2008;4(1):1-16.

11. Choi H, Choi SR, Zhou R, Kung HF, Chen IW. Iron oxide nanoparticles as magnetic resonance contrast agent for tumor imaging via folate receptor-targeted delivery. Acad Radiol. 2004;11(9): 996-1004.

12. Lu AH, Salabas EL, Schüth F. Magnetic nanoparticles: synthesis, protection, functionalization, and application. Angew Chem Int Ed Engl. 2007;46(8):1222-1244.

13. Qin J, Laurent S, Jo YS, et al. A high-performance magnetic resonance imaging T-2 contrast agent. Adv Mater. 2007;19(14):1874-1878.

14. Huh YM, Jun YW, Song HT, et al. In vivo magnetic resonance detection of cancer by using multifunctional magnetic nanocrystals. J Am Chem Soc. 2005; 127(35):12387-12391.

15. Clift MJ, Rothen-Rutishauser B, Brown DM, et al. The impact of different nanoparticle surface chemistry and size on uptake and toxicity in a murine macrophage cell line. Toxicol Appl Pharmacol. November 1, 2008;232(3):418-427. Epub July 1, 2008.

16. Chouly C, Pouliquen D, Lucet I, Jeune JJ, Jallet P. Development of superparamagnetic nanoparticles for MRI: effect of particle size, charge and surface nature on biodistribution. J Microencapsul. 1996;13(3):245-255.

17. Moghimi SM, Hunter AC, Murray JC. Long-circulating and targetspecific nanoparticles: theory to practice. Pharmacol Rev. 2001;53(2): 283-318.

18. Lunov O, Syrovets T, Röcker C, et al. Lysosomal degradation of the carboxydextran shell of coated superparamagnetic iron oxide nanoparticles and the fate of professional phagocytes. Biomaterials. Dec 2010;31(34):9015-9022. Epub August 23, 2010.

19. Artemov D. Molecular magnetic resonance imaging with targeted contrast agents. J Cell Biochem. 2003;90(3):518-524. 
20. Leuschner C, Kumar CS, Hansel W, Soboyejo W, Zhou J, Hormes J. LHRH-conjugated magnetic iron oxide nanoparticles for detection of breast cancer metastases. Breast Cancer Res Treat. Sep 2006;99(2): 163-176. Epub June 3, 2006.

21. Zhang Y, Kohler N, Zhang M. Surface modification of superparamagnetic magnetite nanoparticles and their intracellular uptake. Biomaterials. 2002;23(7):1553-1561.

22. Weitman SD, Lark RH, Coney LR, et al. Distribution of the folate receptor GP38 in normal and malignant cell lines and tissues. Cancer Res. 1992;52(12):3396-3401.

23. Ross JF, Chaudhuri PK, Ratnam M. Differential regulation of folate receptor isoforms in normal and malignant tissues in vivo and in established cell lines. Physiologic and clinical implications. Cancer. 1994;73(9):2432-2443.

24. Parker N, Turk MJ, Westrick E, Lewis JD, Low PS, Leamon CP. Folate receptor expression in carcinomas and normal tissues determined by a quantitative radioligand binding assay. Anal Biochem. 2005;338(2):284-293

25. Jana NR, Chen YF, Peng XG. Size- and shape-controlled magnetic ( $\mathrm{Cr}, \mathrm{Mn}, \mathrm{Fe}, \mathrm{Co}, \mathrm{Ni}$ ) oxide nanocrystals via a simple and general approach. Chem Mater. 2004;16(20):3931-3935.

26. Salgueiriño-Maceira V, Liz-Marzán LM, Farle M. Water-based ferrofluids from FexPt1-x nanoparticles synthesized in organic media. Langmuir. 2004;20(16):6946-6950.

27. Chen ZP, Zhang Y, Zhang S, et al. Preparation and characterization of water-soluble monodisperse magnetic iron oxide nanoparticles via surface double-exchange with DMSA. Colloids Surf A Physicochem Eng Asp. 2008;316(1-3):210-216.

28. Lattuada M, Hatton TA. Functionalization of monodisperse magnetic nanoparticles. Langmuir. 2007;23(4):2158-2168.

29. You J, Li X, de Cui F, Du YZ, Yuan H, Hu FQ. Folate-conjugated polymer micelles for active targeting to cancer cells: preparation, in vitro evaluation of targeting ability and cytotoxicity. Nanotechnology. January 30, 2008;19(4):045102. Epub January 4, 2008.

30. Zhou J, Leuschner C, Kumar C, Hormes J, Soboyejo WO. A TEM study of functionalized magnetic nanoparticles targeting breast cancer cells. Materials Science and Engineering: C. 2006;26(8):1451-1455.

31. Jain TK, Richey J, Strand M, Leslie-Pelecky DL, Flask CA, Labhasetwar V. Magnetic nanoparticles with dual functional properties: drug delivery and magnetic resonance imaging. Biomaterials. Oct 2008;29(29):4012-4021. Epub July 22, 2008.

32. Sun S, Zeng H, Robinson DB, et al. Monodisperse MFe2O4 ( $\mathrm{M}=\mathrm{Fe}$, Co, Mn) nanoparticles. J Am Chem Soc. 2004;126(1):273-279.

33. $\mathrm{Wu} \mathrm{W}, \mathrm{He} \mathrm{Q}$, Jiang C. Magnetic iron oxide nanoparticles: synthesis and surface functionalization strategies. Nanoscale Res Lett. 2008;3(11): $397-415$.
34. Pouliquen D, Le Jeune JJ, Perdrisot R, Ermias A, Jallet P. Iron oxide nanoparticles for use as an MRI contrast agent: pharmacokinetics and metabolism. Magn Reson Imaging. 1991;9(3):275-283.

35. Yokoyama M, Satoh A, Sakurai Y, et al. Incorporation of water-insoluble anticancer drug into polymeric micelles and control of their particle size. J Control Release. 1998;55(2-3):219-229.

36. Marsh M, McMahon HT. The structural era of endocytosis. Science. 1999;285(5425):215-220.

37. Pearse BM, Crowther RA. Structure and assembly of coated vesicles. Annu Rev Biophys Biophys Chem. 1987;16:49-68.

38. Heuser JE, Anderson RG. Hypertonic media inhibit receptor-mediated endocytosis by blocking clathrin-coated pit formation. J Cell Biol. 1989;108(2):389-400.

39. Landmark KJ, DiMaggio S, Ward J, et al. Synthesis, characterization, and in vitro testing of superparamagnetic iron oxide nanoparticles targeted using folic acid-conjugated dendrimers. ACS Nano. 2008;2(4): 773-783.

40. Kohler N, Sun C, Wang J, Zhang M. Methotrexate-modified superparamagnetic nanoparticles and their intracellular uptake into human cancer cells. Langmuir. 2005;21(19):8858-8864.

41. Kohler N, Sun C, Fichtenholtz A, Gunn J, Fang C, Zhang M. Methotrexate-immobilized poly(ethylene glycol) magnetic nanoparticles for MR imaging and drug delivery. Small. 2006;2(6): 785-792.

42. Kim JS, Yoon TJ, Yu KN, et al. Cellular uptake of magnetic nanoparticle is mediated through energy-dependent endocytosis in A549 cells. J Vet Sci. 2006;7(4):321-326.

43. Panyam J, Labhasetwar V. Dynamics of endocytosis and exocytosis of poly(D,L-lactide-co-glycolide) nanoparticles in vascular smooth muscle cells. Pharm Res. 2003;20(2):212-220.

44. Chithrani BD, Chan WC. Elucidating the mechanism of cellular uptake and removal of protein-coated gold nanoparticles of different sizes and shapes. Nano Lett. Jun 2007;7(6):1542-1550. Epub April 28, 2007.

45. Gu J, Xu H, Han Y, et al. The internalization pathway, metabolic fate and biological effect of superparamagnetic iron oxide nanoparticles in the macrophage-like RAW264.7 cell. Sci China Life Sci. Sep 2011;54(9):793-805. Epub September 16, 2011.

46. Rohrer M, Bauer H, Mintorovitch J, Requardt M, Weinmann HJ. Comparison of magnetic properties of MRI contrast media solutions at different magnetic field strengths. Invest Radiol. 2005;40(11): $715-724$.
International Journal of Nanomedicine

\section{Publish your work in this journal}

The International Journal of Nanomedicine is an international, peerreviewed journal focusing on the application of nanotechnology in diagnostics, therapeutics, and drug delivery systems throughout the biomedical field. This journal is indexed on PubMed Central, MedLine, CAS, SciSearch $\AA$, Current Contents ${ }^{\circledR} /$ Clinical Medicine,

\section{Dovepress}

Journal Citation Reports/Science Edition, EMBase, Scopus and the Elsevier Bibliographic databases. The manuscript management system is completely online and includes a very quick and fair peer-review system, which is all easy to use. Visit http://www.dovepress.com/ testimonials.php to read real quotes from published authors. 